\title{
Driven Factors Analysis of China's Irrigation Water Use Efficiency by Stepwise Regression and Principal Component Analysis
}

\author{
Renfu Jia, ${ }^{1}$ Shibiao Fang, ${ }^{2}$ Wenrong Tu, ${ }^{2}$ and Zhilin Sun ${ }^{2}$ \\ ${ }^{1}$ College of Civil Science and Engineering, Yangzhou University, Yangzhou 225127, China \\ ${ }^{2}$ Ocean College, Zhejiang University, Hangzhou 310058, China \\ Correspondence should be addressed to Shibiao Fang; 11434024@zju.edu.cn
}

Received 23 July 2015; Accepted 9 December 2015

Academic Editor: Juan Pavón

Copyright (C) 2016 Renfu Jia et al. This is an open access article distributed under the Creative Commons Attribution License, which permits unrestricted use, distribution, and reproduction in any medium, provided the original work is properly cited.

\begin{abstract}
This paper introduces an integrated approach to find out the major factors influencing efficiency of irrigation water use in China. It combines multiple stepwise regression (MSR) and principal component analysis (PCA) to obtain more realistic results. In real world case studies, classical linear regression model often involves too many explanatory variables and the linear correlation issue among variables cannot be eliminated. Linearly correlated variables will cause the invalidity of the factor analysis results. To overcome this issue and reduce the number of the variables, PCA technique has been used combining with MSR. As such, the irrigation water use status in China was analyzed to find out the five major factors that have significant impacts on irrigation water use efficiency. To illustrate the performance of the proposed approach, the calculation based on real data was conducted and the results were shown in this paper.
\end{abstract}

\section{Introduction}

Agriculture is the basis for human survival, consuming up to $75 \%$ of current human water use to feed about 7.2 billion people in the world [1]. At present, intensifying water scarcity and water pollution cause the freshwater resources for irrigation to reduce, hindering agriculture's development [2]. And then the demand of food and living space for the additional 1.8 billion people by 2050 according to population projections will put further enormous pressure on irrigation water use and limit the arable land $[3,4]$. In other words, future increases in agricultural production will have to come mainly by growing more food on existing land and water [5]. And the decrease of water resources and severe environmental pollution are changing the way the agriculture is developing, with emphasis on sustainable and clean development [6]. As such, improving the efficiency of irrigation water use attracts more and more attention currently and this is consistent with the sustainable development.

In China, about $80 \%$ of production of food comes from irrigated farmland. The irrigated area reaches to $5 \times 10^{7}$ hectares, accounting for about $95 \%$ of arable land [7]. And the irrigation water use is always the biggest consumer of water. However, the proportion of water use for irrigation has been narrowing from $80 \%$ in 1970 s to less than $60 \%$ at present. In the past three years, total amount of water use in China is about 614 billion $\mathrm{m}^{3} /$ year on average, among which the irrigation water use is about 346.9 billion $\mathrm{m}^{3} /$ year accounting for about $56.5 \%$ [8-10]. And the proportion for irrigation continues to decline in its trend, which will widen the gap between supply and demand of irrigation water use.

In addition, the water-wasting phenomena always exist in the agriculture. Compared with the developed countries' irrigation water use efficiency of about $70 \%-80 \%$, China's water utilization efficiency is very low. China's irrigation water use efficiency is about $45 \%$ at present, wasting more than $50 \%$ of water in the process of water delivery and irrigation. Therefore, the grain production is also very low in China; only $1 \mathrm{~kg}$ grain can be produced by $1 \mathrm{~m}^{3}$ of water [11]. Given all of the above, the government of China put forward the most stringent water resource management to enhance the water use 
efficiency. Under this situation, firstly the government needs to find out the major factors which influence the water use efficiency significantly, and these major factors can be called driven factors.

In real world, the correlations among the factors influencing the irrigation water use efficiency (IWUE), namely, multicollinearity, will increase the complexity of factor analysis. As such, PCA is introduced to the driven factor analysis of IWUE [12]. PCA can compress data by reducing the dimensionality of a data set which includes a large number of interrelated variables without losing information. After compression, the original data is transformed into a new set of variables, namely, new principal components, which are uncorrelated to each other [13].

In this paper, to overcome the mentioned weakness of the stepwise regression, PCA approach is introduced and combined with the stepwise regression for driven factors analysis of irrigation water use efficiency in China. First, stepwise regression is used to find out the explanatory variables which have no multicollinearity with other variables. Second, the PCA approach is used to reduce the number of the remaining variables transforming them into a new set of variables, called principal components, which are uncorrelated with each other. At last, a linear regression is established for modeling the relationship between a scalar dependent variable (IWUE) and one or more explanatory variables (driven factors).

The rest of the paper is organized as follows: "Review of the Research on Factor Analysis" provides a detailed review of the state of the art on the methods that can be used to solve similar problems. Then this paper justifies the interest of the proposed approach with respect to others. "Methodology" introduces the methodology of the proposed model. Then in the "Driven Factors Screening," the process for selecting driven factors has been explained. In "Calculation," the case study is presented to show the computation process. Finally, the results and conclusions are summarized in "Results" and "Conclusions," respectively.

\section{Review of the Research on Factor Analysis}

2.1. Subjective Weighting Methods. Subjective weighting methods evaluate the factors using qualitative measures according to empirical expertise, such as AHP (Analytic Hierarchy Process), Delphi method, fuzzy comprehensive method, DARE method, and order relation analysis method. Among the subjective weighting methods, AHP method is a common mean for deciding the indicators' weight which is frequently used in various fields. For example, Wang et al. [14] used the AHP-GRA analytic hierarchy process-gray relational analysis method to make the decision for ergonomic evaluation.

The biggest advantage of subjective weighting method is that it could reasonably determine the order of all the indicators. That is to say, though the subjective weighting method cannot well know the weighting coefficient of each indicator, it can effectively ensure the sequence of given indicators according to their influencing degrees. Then the biggest disadvantage of this method is its subjectiveness and randomness, because the different the experts, the different the weighting coefficients. As such, in some cases, applying subjective weighting methods may cause the significant difference compared with actual situation.

2.2. Objective Weighting Methods. Determinations or evaluation results of objective weighting methods are based on the strong mathematical theory reducing the burden of decision-makers. Except the popular objective methods like least squares and eigenvector method $[15,16]$, there are other advanced methods such as mean-squared deviation weight method, simple correlation function method, principal component analysis, and factor analysis [17, 18]. To date, the research history of objective weighting methods is still short and immature. And this weighting method is confined to the realistic problem domain, which fails to own the generality. In addition, the computational methods are relatively complex without the consideration of subjective intent of the policy makers, causing poor participation.

Among the mentioned objective weighting methods above, principal component analysis (PCA) is a statistical procedure that uses an orthogonal transformation to convert a set of observations of possibly correlated variables into a set of values of linearly uncorrelated variables called principal components. The number of principal components is less than or equal to the number of original variables. This transformation is defined in such a way that the first principal component has the largest possible variance (i.e., accounts for as much of the variability in the data as possible), and each succeeding component in turn has the highest variance possible under the constraint that it is orthogonal to the preceding components. The resulting vectors are an uncorrelated orthogonal basis set. The principal components are orthogonal because they are the eigenvectors of the covariance matrix, which is symmetric. PCA is sensitive to the relative scaling of the original variables.

The limitations of PCA areas follows: (1) getting the weight of principal components rather than the objective weight of each independent indicator and (2) invalid results once the correlations among indicators are too low.

2.3. Advantages of Proposed Methods. To sum up, the determination of indicators' weighting in the multiobjective decision is significantly important. Weighting is a complicated metric for subjective assessment and objective reality. It reflects the indicator's important level in the evaluation process. Rationality of weighting's value affects the judging results significantly. As such, we need to figure out the value of indicator's weighting effectively and scientifically, as well as the appropriate weighting methods. In this paper, the proposed methods were put forward combining the subjective and objective weighting methods. And the methods' interests compared with other methods are shown in the following.

There were too many original indicators collected from the literature in the beginning, and we just need some of them. So we used the subjective weighting methods to screen the indicators firstly because it could reasonably determine the order of all the indicators. The useless indicators we deleted were meaningless for the assessment, so their weighting values were not necessary to be estimated accordingly 
(i.e., why we denied objective methods). We chose Delphi method to get the effective indicators so that the efficiency of assessment operation was relatively high.

Then, the driven factors after screening need to be dealt with on the strong basis of mathematical theory because we need to know their meanings that influence the water use efficiency. We used the method of correlation coefficient and modified PCA method to analyze the indicators. In accordance with the limitations of PCA, we introduced the MSR to reduce the invalid results. And we abstracted all the principal components to retain the original data so we can get the objective weight of each independent indicator.

\section{Methodology}

3.1. PCA Model. According to $[13,19,20]$, PCA is applied in this paper to eliminate the multicollinearity among the variables.

After literature analysis, a lot of factors that affect the irrigation water use efficiency have been found. Then 22 driven factors were introduced to the irrigation water use efficiency analysis and taken as the variables in the PCA model. For the period of 1997-2010, 14 samples were collected for analysis of IWUE in China. Consider a data matrix, $\mathbf{X}$, with column-wise zero empirical means (the sample mean of each column has been shifted to zero), where each of the $n$ rows represents a different repetition of the experiment, and each of the $p$ columns gives a particular kind of datum. Driven factors are exhibited in $p$ columns, and the data matrix $\mathbf{X}$ is shown in the following:

$$
\mathbf{X}=\left(\begin{array}{cccc}
x_{11} & x_{12} & \cdots & x_{1 p} \\
x_{21} & x_{22} & \cdots & x_{2 p} \\
\cdots & \cdots & \cdots & \cdots \\
x_{n 1} & x_{n 2} & \cdots & x_{n p}
\end{array}\right)
$$

In matrix $\mathbf{X}, n$ represents the number of samples and $p$ represents the number of driven factors.

Mathematically, the transformation is defined by a set of $p$-dimensional vectors of weight or loadings $\mathbf{L}_{(j)}=$ $\left(l_{1}, \ldots, l_{p}\right)_{(j)}$ that map each row vector $\mathbf{X}_{(i)}=\left(x_{1}, \ldots, x_{p}\right)_{(i)}$ of $\mathbf{X}$ to a new vector of principal component scores $\mathbf{Z}_{(i)}=$ $\left(z_{1}, \ldots, z_{p}\right)_{(i)}$, given by

$$
\begin{array}{r}
\mathbf{Z}_{m(i)}=\mathbf{X}_{(i)} \cdot \mathbf{L}_{(j)} \\
\quad i=1,2, \ldots, n j=1,2, \ldots, m m<p .
\end{array}
$$

As such, the individual variables of $\mathbf{Z}$ considered over the data set successively inherit the maximum possible variance from $\mathbf{X}$, with each loading vector $\mathbf{L}$ constrained to be a unit vector. And the new variables in $\mathbf{Z}$ are uncorrelated with each other. New variables are presented as follows:

$$
\begin{gathered}
z_{1(i)}=l_{11} x_{1(i)}+l_{12} x_{2(i)}+\cdots+l_{1 p} x_{p(i)} \\
z_{2(i)}=l_{21} x_{1(i)}+l_{22} x_{2(i)}+\cdots+l_{2 p} x_{p(i)} \\
\vdots \\
z_{m(i)}=l_{m 1} x_{1(i)}+l_{m 2} x_{2(i)}+\cdots+l_{m p} x_{p(i)} .
\end{gathered}
$$

For the first principal component $z_{1}$ in the above, the corresponding loading vector $\mathbf{L}_{(1)}$ has to satisfy

$$
\begin{aligned}
\mathbf{L}_{(1)} & =\underset{\|\mathbf{L}\|=1}{\arg \max }\left\{\sum_{i}\left(z_{1}\right)_{(i)}^{2}\right\} \\
& =\underset{\|\mathbf{L}\|=1}{\arg \max }\left\{\sum_{i}\left(x_{(i)} \cdot l\right)^{2}\right\}=\underset{\|\mathbf{L}\|=1}{\arg \max }\left\{\|\mathbf{X} l\|^{2}\right\} \\
& =\underset{\|\mathbf{L}\|=1}{\arg \max }\left\{l^{\mathbf{T}} \mathbf{X}^{\mathbf{T}} \mathbf{X} l\right\} .
\end{aligned}
$$

A standard result for a symmetric matrix such as $\mathbf{X}^{\mathrm{T}} \mathbf{X}$ is that the quotient's maximum possible value is the largest eigenvalue of the matrix, which occurs when $\mathbf{L}_{(1)}$ is the corresponding eigenvector. With $\mathbf{L}_{(1)}$ found, the first component of a data vector $z_{(i)}$ can then be given as a score $z_{1(i)}=x_{(i)} \cdot l_{(1)}$ in the transformed coordinates, or as the corresponding vector in the original variables.

The $k$ th component can be found by subtracting the first $k-1$ principal components from $\mathbf{X}$ :

$$
\widehat{\mathbf{X}}_{k}=\mathbf{X}-\sum_{s=1}^{k-1} \mathbf{X} l_{(s)} l_{(s)}^{\mathrm{T}} .
$$

Then we find the loading vector which extracts the maximum variance from this new data matrix in the following:

$$
\begin{aligned}
\mathbf{L}_{(k)} & =\underset{\|\mathbf{L}\|=1}{\arg \max }\left\{\left\|\widehat{\mathbf{X}}_{k-1} l\right\|^{2}\right\} \\
& =\underset{\|\mathbf{L}\|=1}{\arg \max }\left\{\frac{l^{\mathrm{T}} \widehat{\mathbf{X}}_{k-1}^{\mathbf{T}} \widehat{\mathbf{X}}_{k-1} l}{l^{\mathbf{T}} l}\right\} .
\end{aligned}
$$

It turns out that this gives the remaining eigenvectors of $\mathbf{X}^{\mathbf{T}} \mathbf{X}$, with the maximum values for the quantity in brackets given by their corresponding eigenvalues. Then the $k$ th principal component of a data vector $x_{(i)}$ can therefore be given as a score $z_{k(i)}=x_{(i)} \cdot l_{(k)}$ in the transformed coordinates or as the corresponding vector in the space of the original variables, where $l_{(k)}$ is the $k$ th eigenvector of $\mathbf{X}^{\mathrm{T}} \mathbf{X}$.

The full principal components decomposition of $\mathbf{X}$ can therefore be given as $\mathbf{T}=\mathbf{X} \cdot \mathbf{L}$.

3.2. Stepwise Regression. In statistics, stepwise regression includes regression models in which the choice of predictive variables is carried out by an automatic procedure [21, 22]. Usually, this takes the form of a sequence of $F$-tests or $t$-tests, but other techniques are possible, such as adjusted $R^{2}$, Akaike information criterion, Bayesian information criterion, Mallows' Cp, PRESS, or false discovery rate. The frequent practice of fitting the final selected model followed by reporting estimates and confidence intervals without adjusting them to take the model building process into account has led to calls to stop using stepwise model building altogether $[23,24]$ or to at least make sure model uncertainty is correctly reflected $[25,26]$. 


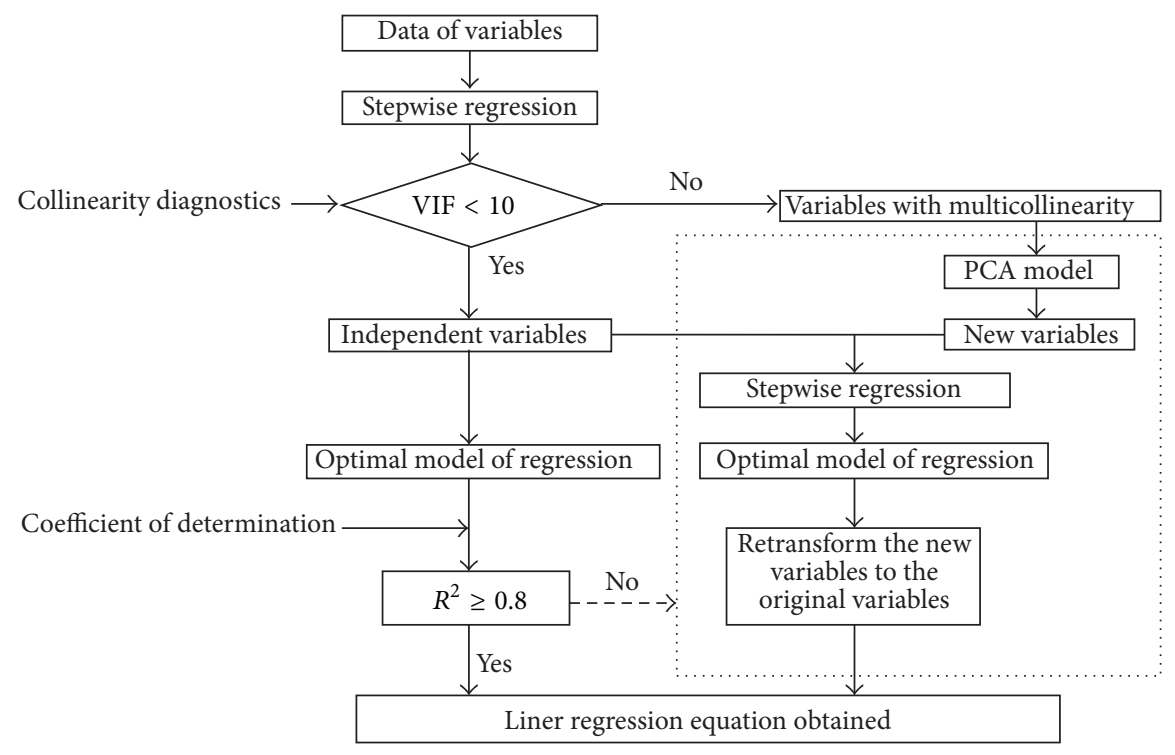

FIGURE 1: Flowchart of irrigation water use efficiency analysis.

Stepwise regression includes three main approaches: forward selection, backward elimination, and bidirectional elimination. A widely used algorithm was first proposed by [27]. This is an automatic procedure for statistical model selection in cases where there are a large number of potential explanatory variables, and no underlying theory on which to base the model selection. The procedure is used primarily in regression analysis, though the basic approach is applicable in many forms of model selection. This is a variation on forward selection. At each stage in the process, after a new variable is added, a test is made to check if some variables can be deleted without appreciably increasing the residual sum of squares (RSS). The procedure terminates when the measure is (locally) maximized or when the available improvement falls below some critical value.

One of the main issues with stepwise regression is that it searches a large space of possible models. Hence it is prone to the overfitting of the data. In other words, stepwise regression will often fit much better in sample than it does on new outof-sample data. This problem can be mitigated if the criterion for adding (or deleting) a variable is stiff enough. The key line in the sand is at what can be thought of as the Bonferroni point, namely, how significant the best spurious variable should be based on chance alone. On $t$-statistic scale, this occurs at about $\sqrt{2 \log p}$, where $p$ is the number of predictors. This fence turns out to be the right trade-off between overfitting and missing signal. If we look at the risk of different cutoffs, then using this bound will be within a $2 \log p$ factor of the best possible risk. Any other cutoff will end up having a larger such risk inflation $[28,29]$.

3.3. Stepwise Regression-PCA Model. The purpose of irrigation water use efficiency study is to find out five major driven factors from all the driven factors of China. In other words, the final results must be presented using the original data, and the number of chosen factors cannot be less than five. The major challenges in the mathematical model selecting are shown below.

(1) While eliminating the multicollinearity, the factors strongly unrelated with other factors must be contained.

(2) The variables which actually carry data information must be included as many as possible.

(3) The data can be retransformed back to its origin.

As such, the stepwise regression model combined with PCA model is applied in this paper. Mathematically, one or some factors among these driven factors may be uncorrelated with other factors. So we use variance inflation factor (VIF) which quantifies the severity of multicollinearity in an ordinary least squares regression analysis to measure how much the variance (the square of the estimate's standard deviation) of an estimated regression coefficient is increased because of collinearity. Then the factors uncorrelated with others can be found. For the remaining factors, we use PCA model to eliminate their multicollinearity by transforming them into a new set of variables while carrying all the original information. At last, stepwise regression is used to establish an optimal regression model to fit the data. The flowchart of irrigation water use efficiency analysis is shown in Figure 1.

\section{Driven Factors Screening}

The change of agricultural water use efficiency is driven by multifactors such as climatic conditions, resource endowment, irrigation technology and management, and capital investment. Through literature review [30-45], we have listed 


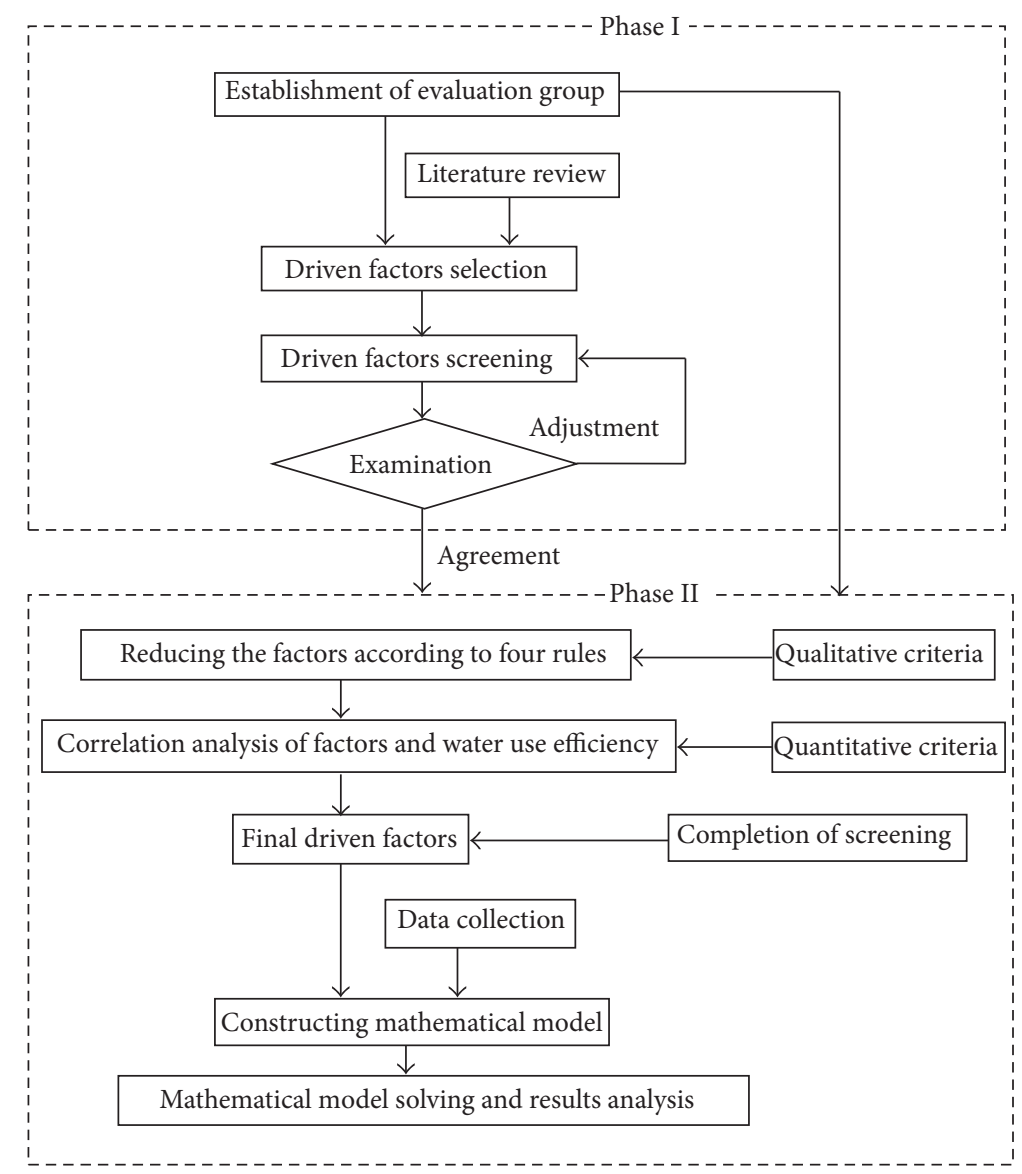

FIGURE 2: Screening and classification process chart of driven factors.

the driven factors as many as possible. Then these driven factors were screened according to four rules in the following.

(1) Comprehensive. The driven factors must be related to the irrigation water use efficiency closely and the factors can reflect the China's agricultural development status synthetically.

(2) Objectivity. The driven factors must be objective to eliminate the subjective factors as far as possible. As such, the experts could judge the importance of factors fairly.

(3) Independence. Although it is inevitable that the interconnected relationship exists among variables, we could choose the factors inferred with high independent in accordance with the experts' empirical conclusion.

(4) Convenient. Other than the three rules above, we must remove the factors whose data cannot be collected for convenient. It is helpful to decrease the difficulties of this study.

According to the four rules above, the flowchart of driven factors screening is shown in Figure 2. After the screening, the final driven factors are shown in the Table 1.

\section{Calculation}

Taking the data of 22 independent variables and IWUC of China in the period of 1997-2010 into consideration, we have conducted the stepwise regression and principal component analysis. The data used here come from National Bureau of Statistics of China, 2011-2014.

5.1. Stepwise Regression for Collinearity Diagnostics. The collinearity can be diagnosed by Tolerance. Tolerance is the ratio of residual sum of squares to total sum of squares after regression analyzing one independent variable (as the dependent variable) and the other independent variables. The smaller this index is, the more serious the collinearity is. That is to say this independent variable can be predicted by the remaining independent variables precisely. The criterion of Tolerance in this paper is 0.1: namely, if an independent variable's Tolerance is less than 0.1, there will exist collinearity. Variance inflation factor (VIF) is the reciprocal of Tolerance.

The outcome of collinearity diagnosis by SPSS is shown in Table 2.

The first industrial output (FIO) is the only indicator which does not relate to other 21 indicators. However, the coefficient of determination $R^{2}=0.286$ indicating the data does not fit the statistical model very well; there remains 
TABLE 1: Explanation of the selected driven factors.

\begin{tabular}{|c|c|c|c|}
\hline Indicators & Explanation & Classification & $\begin{array}{l}\text { Correlation coefficient with } \\
\text { irrigation water use efficiency }\end{array}$ \\
\hline Annual precipitation (AP) & $\begin{array}{l}\text { The total rainfall in a year; } \\
\text { millimetre }(\mathrm{mm})\end{array}$ & Climatic condition & 0.36 \\
\hline $\begin{array}{l}\text { Average temperature per year } \\
\text { (AT) }\end{array}$ & $\begin{array}{l}\text { Average temperature according to } \\
\text { daily temperature in a year; }{ }^{\circ} \mathrm{C}\end{array}$ & Climatic condition & 0.075 \\
\hline Rainfall frequency $(\mathrm{RF})$ & $\begin{array}{l}\text { Accumulated frequency of rainfall } \\
\text { of one year }\end{array}$ & Climatic condition & -0.16 \\
\hline Drought index (DI) & $\begin{array}{l}\text { Dividing total evaporation by } \\
\text { precipitation in a year }\end{array}$ & Climatic condition & -0.337 \\
\hline Proportion of farmers (PR) & $\begin{array}{l}\text { Proportion of farmers in total } \\
\text { employment }\end{array}$ & Human resources & 0.482 \\
\hline Arable land area (AA) & $\begin{array}{l}\text { Agricultural land, reclaimed } \\
\text { tideland and river filed; }\left(10^{3} \text { ha) }\right.\end{array}$ & Resource endowment & -0.521 \\
\hline Per capita arable land (PA) & $\begin{array}{l}\text { Dividing arable land by total } \\
\text { population in China }\end{array}$ & Resource endowment & 0.46 \\
\hline $\begin{array}{l}\text { Local water resource amount } \\
\text { (LW) }\end{array}$ & $\begin{array}{l}\text { The amount of local surface water } \\
\text { resources and groundwater } \\
\text { resources quantity; }\left(10^{8} \mathrm{~m}^{3}\right)\end{array}$ & Resource endowment & 0.457 \\
\hline $\begin{array}{l}\text { Per capita water resource } \\
\text { amount }(\mathrm{PW})\end{array}$ & $\begin{array}{l}\text { Local water resource } \\
\text { amount/population }\end{array}$ & Resource endowment & 0.526 \\
\hline $\begin{array}{l}\text { Per capita water consumption } \\
\text { (PWC) }\end{array}$ & $\begin{array}{l}\text { Total water consumption in a } \\
\text { year/population }\end{array}$ & Resource endowment & -0.4 \\
\hline $\begin{array}{l}\text { Per capita income of farmers } \\
\text { (PIF) }\end{array}$ & Yuan/year & Economic condition & -0.5 \\
\hline Per capita GDP (PGDP) & Yuan/year & Economic condition & -0.5 \\
\hline First industrial output (FIO) & $\begin{array}{l}\text { Agricultural output proportion } \\
\text { accounted for the total industrial } \\
\text { output }\end{array}$ & Economic condition & 0.535 \\
\hline $\begin{array}{l}\text { Rice planting area proportion } \\
\text { (RPA) }\end{array}$ & $\begin{array}{l}\text { Rice planting area proportion in the } \\
\text { total sown area }\end{array}$ & Economic condition & 0.1 \\
\hline $\begin{array}{l}\text { Grain crop area proportion } \\
\text { (GCA) }\end{array}$ & $\begin{array}{l}\text { Grain crop area proportion in the } \\
\text { total sown area }\end{array}$ & Economic condition & 0.1 \\
\hline Crop production $(\mathrm{CP})$ & $10^{4}$ ton $\left(10^{4} \mathrm{t}\right)$ & Economic condition & -0.3 \\
\hline $\begin{array}{l}\text { Spending on science and } \\
\text { technology (SST) }\end{array}$ & $\begin{array}{l}\text { Science and technology spending } \\
\text { proportion accounted for the } \\
\text { financial expenditure }\end{array}$ & Technology condition & -0.4 \\
\hline $\begin{array}{l}\text { Water-saving irrigation area } \\
\text { (WSIA) }\end{array}$ & $10^{3}$ Hectare $\left(10^{3} \mathrm{ha}\right)$ & Technology condition & -0.6 \\
\hline $\begin{array}{l}\text { Highly efficient water-saving } \\
\text { irrigation area (HWSIA) }\end{array}$ & $10^{3}$ Hectare $\left(10^{3}\right.$ ha $)$ & Technology condition & -0.5 \\
\hline Effective irrigation area (EIA) & $\begin{array}{l}\text { Land area truly irrigated; } 10^{3} \\
\text { Hectare }\left(10^{3} \mathrm{ha}\right)\end{array}$ & Technology condition & -0.5 \\
\hline Spending on agriculture (SA) & Spending proportion on agriculture & Management indices & -0.3 \\
\hline Water price (WP) & Yuan & Management indices & -0.5 \\
\hline $\begin{array}{l}\text { Irrigation water use coefficient } \\
\text { (IWUC) }\end{array}$ & $\begin{array}{l}\text { Dividing water consumption in } \\
\text { farmland by water use for irrigation } \\
\text { in a year }\end{array}$ & $\begin{array}{l}\text { Research object (dependent } \\
\text { variable) in this paper's study }\end{array}$ & 1 \\
\hline
\end{tabular}

Note: the economic indices in this table are calculated at comparable prices.

TABLE 2: Collinearity diagnostics.

\begin{tabular}{rrrccccc}
\hline Model & $R$ & $R^{2}$ & Adjusted $R^{2}$ & Std. error of the estimate & Correlation & Tolerance & VIF \\
\hline 1 & $0.535^{\mathrm{a}}$ & 0.286 & 0.227 & 0.00771 & 0.535 & 1.0 & 1.0 \\
\hline${ }^{\mathrm{a}}$ First industrial output. & & & & & &
\end{tabular}




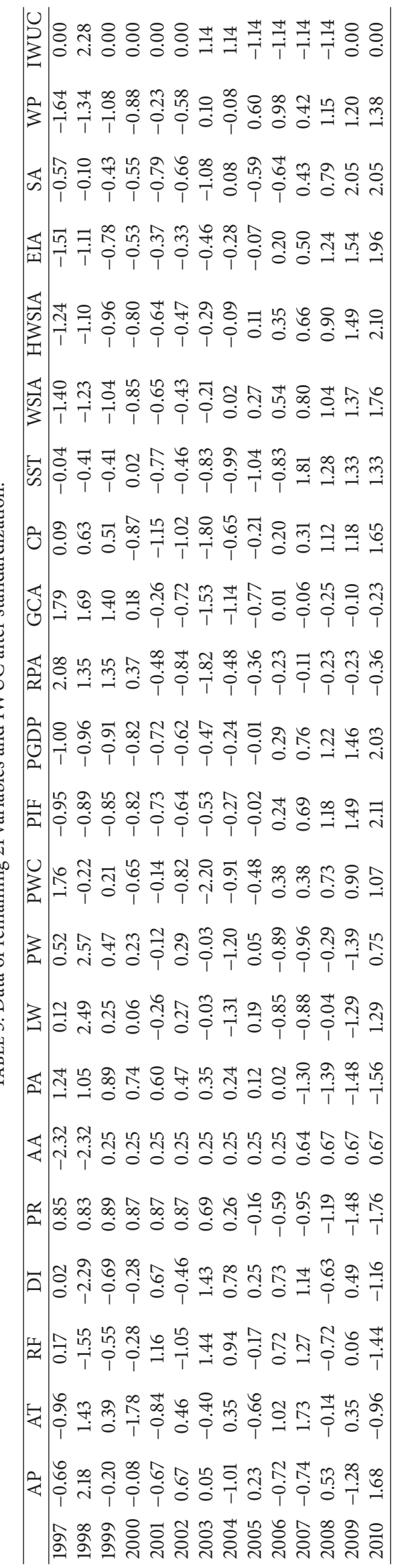


TABLE 4: Total variance of interpretation.

\begin{tabular}{lccc}
\hline \multirow{2}{*}{ Components } & \multicolumn{3}{c}{ Initial eigenvalue } \\
& Total & Variance (\%) & Cumulative (\%) \\
\hline 1 & 10.511 & 50.054 & 50.054 \\
2 & 5.667 & 26.985 & 77.039 \\
3 & 2.389 & 11.378 & 88.417 \\
4 & 1.039 & 4.947 & 93.364 \\
5 & 0.454 & 2.160 & 95.524 \\
6 & 0.435 & 2.073 & 97.597 \\
7 & 0.225 & 1.070 & 98.667 \\
8 & 0.126 & 0.600 & 99.267 \\
9 & 0.067 & 0.320 & 99.588 \\
10 & 0.038 & 0.179 & 99.767 \\
11 & 0.030 & 0.142 & 99.909 \\
12 & 0.012 & 0.057 & 99.965 \\
13 & 0.007 & 0.035 & 100.00 \\
\hline
\end{tabular}

$e=\sqrt{1-R^{2}}=0.845$ which can be enhanced. Then we need to introduce other variables without collinearity.

5.2. Principal Component Analysis for Remaining Variables. As mentioned above, only one factor has been picked up; the remaining 21 variables related to each other. As such, the principal component analysis has been conducted to eliminate the collinearity among the 21 variables, figuring out the principal factors under the condition that the original data information must be retained.

At first, the data standardization of 21 variables is shown in Table 3. Then these standardized data have been used in the SPSS to conduct the principal component analysis. The total variance of interpretation for the 21 variables is shown in Table 4. And we got the principal component score coefficient matrix, shown in Table 5.

According to principal components score coefficient matrix, we introduced the original data forming new data of principal components. For example, the data of first component (FAC_1) was obtained according to the following equation:

$$
\begin{aligned}
\mathbf{F}_{1}= & -0.111 \mathbf{X}_{1 \mathbf{t}}+0.106 \mathbf{X}_{2 \mathbf{t}}+0.012 \mathbf{X}_{3 \mathbf{t}}+0.196 \mathbf{X}_{4 \mathbf{t}} \\
& -0.965 \mathbf{X}_{5 \mathbf{t}}+0.680 \mathbf{X}_{6 \mathbf{t}}-0.981 \mathbf{X}_{7 \mathbf{t}}-0.368 \mathbf{X}_{8 \mathbf{t}} \\
& -0.557 \mathbf{X}_{9 \mathbf{t}}+0.338 \mathbf{X}_{10 \mathbf{t}}+0.973 \mathbf{X}_{11 \mathbf{t}}+0.981 \mathbf{X}_{12 \mathbf{t}} \\
& -0.444 \mathbf{X}_{13 \mathbf{t}}-0.425 \mathbf{X}_{14 t}+0.573 \mathbf{X}_{15 t} \\
& +0.707 \mathbf{X}_{16 \mathbf{t}}+0.986 \mathbf{X}_{17 t}+0.982 \mathbf{X}_{18 t} \\
& +0.976 \mathbf{X}_{19 t}+0.817 \mathbf{X}_{20 \mathbf{t}}+0.928 \mathbf{X}_{21 \mathbf{t}}
\end{aligned}
$$

where $\mathbf{F}_{1}$ is the new data of FAC_1 and $\mathbf{X}_{i \mathbf{t}}$ is the original data of 21 variables; $i=1,2, \ldots, 21 ; \mathbf{t}=1997,1998, \ldots, 2010$.

As such, the numerical matrix of 13 principal components was listed in Table 6. Because the first industrial output (FIO) has been picked up, its standardized data is also listed in Table 6.
5.3. Multivariate Linear Regression Analysis. Based on the stepwise regression and principal component analysis, the 14 independent variables which are not related to each other have been found. After principal component analysis, we could see that the first three components contribute about $88.42 \%$ to the total variance. Then combined with the variable of FIO, it is considered that the FAC_ 4 also could be included into the linear regression. Namely, the first four components and the FIO have been considered in multivariate linear regression analysis taking the IWUC as the dependent variable.

Then the results after multivariate linear regression analysis are shown in Table 7, and the coefficients of regression are shown in Table 8.

Table 7 indicates that the introduction of principal components affected the dependent variable positively, because the determination coefficient $R^{2}$ increased along with the introduction of principal components step by step. And $R^{2}=$ $0.81>0.8$, which is big enough according to the criterion in Figure 1. So we got the regression equation:

$$
\begin{aligned}
y= & 0.287 x_{\mathrm{FAC} \__{-}}-0.144 x_{\mathrm{FAC} \__{2}}-0.432 x_{\mathrm{FAC} \_3} \\
& +3.774 x_{\mathrm{FIO}}+0.509 x_{\mathrm{FAC}_{-} 4}-0.003
\end{aligned}
$$

\section{Results}

Table 6 represents the projections of original factors on the components and we get four principal components and one original driven factor according to the regression equation. As such, we need to get other original driven factors by formula conversion using Table 9, based on (7) and (8).

Then five major driven factors have been selected in Table 10, because they have the large regression coefficients relatively, affecting the regression equation significantly.

\section{Conclusions}

The enforcement of "Efficient Red Line" is the core of "the most strict water management institution." This paper made a research on the irrigation water use efficiency serving for the dynamic management of water resources in China. The main aim of this paper is to improve the sustainable water resources use so that China's economy and society can develop smoothly.

Through the literature data research and survey, there are 22 indicators that have been selected as the driven factors. By the experts discussion and correlation analysis, the index system of irrigation water use efficiency has been established. And this paper analyzed a variety of mathematical models in order to pick up the most appropriate methods. After analysis, the MSR and PCA were selected and modified to fulfill our requirements for research. At last, the major driven factors influencing China's irrigation water use efficiency mostly were found out. The lessons learned from the application of the methods, in view of the results and the process, are shown in the following, as well as the consideration that how the proposed approach can be reused in similar problems and how it can be improved. 
TABle 5: Principal components score coefficient matrix.

\begin{tabular}{|c|c|c|c|c|c|c|c|c|c|c|c|c|c|}
\hline & \multicolumn{13}{|c|}{ Components } \\
\hline & 1 & 2 & 3 & 4 & 5 & 6 & 7 & 8 & 9 & 10 & 11 & 12 & 13 \\
\hline AP & -0.111 & 0.705 & -0.676 & 0.099 & 0.106 & 0.036 & 0.067 & -0.039 & -0.032 & 0.033 & -0.047 & 0.029 & 0.024 \\
\hline AT & 0.106 & 0.073 & 0.185 & 0.969 & -0.084 & -0.011 & 0.005 & -0.033 & 0.042 & 0.017 & 0.000 & 0.001 & -0.007 \\
\hline $\mathrm{RF}$ & 0.012 & -0.854 & 0.328 & 0.092 & 0.324 & 0.090 & 0.078 & 0.162 & 0.036 & -0.018 & -0.085 & 0.022 & 0.006 \\
\hline DI & 0.196 & -0.912 & 0.253 & 0.001 & 0.219 & 0.048 & 0.047 & 0.011 & -0.009 & 0.077 & 0.079 & -0.036 & 0.005 \\
\hline PR & -0.965 & -0.180 & -0.074 & -0.049 & -0.106 & 0.088 & -0.027 & 0.000 & 0.085 & 0.001 & -0.013 & -0.022 & 0.026 \\
\hline AA & 0.680 & -0.480 & -0.233 & -0.097 & -0.406 & 0.061 & 0.245 & 0.102 & 0.041 & 0.055 & -0.016 & -0.001 & -0.005 \\
\hline PA & -0.981 & -0.068 & 0.015 & -0.063 & -0.024 & -0.146 & -0.033 & 0.029 & 0.035 & 0.024 & 0.040 & 0.047 & 0.013 \\
\hline LW & -0.368 & 0.762 & -0.483 & 0.022 & 0.177 & 0.041 & 0.090 & 0.070 & 0.040 & 0.026 & 0.013 & -0.022 & -0.022 \\
\hline PW & -0.557 & 0.715 & -0.373 & 0.015 & 0.155 & 0.059 & 0.064 & 0.070 & 0.044 & 0.009 & 0.018 & -0.024 & -0.014 \\
\hline PWC & 0.338 & 0.581 & 0.650 & -0.205 & 0.088 & -0.131 & 0.109 & -0.165 & 0.130 & 0.036 & -0.044 & -0.009 & -0.006 \\
\hline PIF & 0.973 & 0.205 & -0.032 & -0.031 & 0.078 & -0.030 & -0.017 & 0.010 & 0.002 & 0.020 & 0.009 & 0.007 & 0.025 \\
\hline PGDP & 0.981 & & -0.035 & -0.015 & & & -0.005 & & & & 0.002 & 0.011 & 0.023 \\
\hline RPA & -0.444 & 0.643 & & -0.077 & -0.061 & -0.047 & 0.025 & 0.074 & -0.112 & 0.051 & -0.033 & 0.013 & -0.033 \\
\hline GCA & -0.425 & 0.707 & 0.530 & 0.024 & -0.015 & 0.006 & 0.127 & 0.100 & 0.039 & -0.056 & 0.079 & 0.030 & 0.013 \\
\hline $\mathrm{CP}$ & 0.573 & 0.735 & 0.283 & 0.073 & -0.064 & -0.153 & 0.024 & 0.098 & -0.060 & 0.003 & -0.016 & -0.046 & 0.043 \\
\hline SST & 0.707 & 0.389 & 0.258 & -0.017 & 0.013 & 0.519 & 0.067 & -0.073 & -0.041 & -0.024 & 0.017 & 0.006 & 0.002 \\
\hline WSIA & 0.986 & -0.024 & -0.114 & 0.042 & 0.054 & -0.080 & 0.004 & -0.014 & -0.027 & 0.033 & 0.011 & 0.020 & -0.015 \\
\hline HWSIA & 0.982 & 0.079 & -0.109 & -0.019 & 0.065 & -0.057 & -0.038 & 0.024 & 0.030 & 0.062 & 0.038 & 0.031 & -0.003 \\
\hline EIA & 0.976 & 0.098 & -0.141 & -0.067 & -0.062 & -0.003 & 0.015 & 0.015 & 0.072 & -0.059 & 0.005 & 0.015 & -0.005 \\
\hline SA & 0.817 & 0.436 & 0.101 & -0.053 & -0.061 & 0.108 & -0.303 & 0.130 & 0.077 & 0.011 & -0.013 & -0.010 & -0.013 \\
\hline WP & 0.928 & -0.164 & -0.180 & 0.027 & 0.086 & -0.224 & 0.102 & 0.010 & -0.021 & -0.095 & 0.011 & -0.017 & -0.019 \\
\hline
\end{tabular}

TABLE 6: The 13 principal components.

\begin{tabular}{|c|c|c|c|c|c|c|c|c|c|c|c|c|c|}
\hline FAC_1 & FAC_2 & FAC_3 & FAC_4 & FAC_5 & FAC_6 & FAC_7 & FAC_8 & FAC_9 & FAC_10 & FAC_11 & FAC_12 & FAC_13 & FIO \\
\hline-13.0 & 3.76 & 4.73 & -1.19 & 0.77 & -0.32 & -0.11 & -0.05 & 0.00 & -0.13 & 0.02 & -0.04 & -0.03 & 1.82 \\
\hline-14.1 & 11.59 & -1.63 & 1.79 & 0.39 & -0.27 & -0.06 & 0.11 & -0.03 & -0.16 & 0.01 & -0.02 & -0.03 & 1.55 \\
\hline-8.92 & 2.90 & 1.71 & 0.22 & -0.82 & -0.28 & 0.23 & 0.26 & 0.03 & -0.06 & 0.01 & -0.03 & -0.02 & 1.15 \\
\hline-7.74 & -0.95 & -0.60 & -1.74 & -0.40 & 0.35 & -0.04 & 0.13 & -0.06 & -0.11 & 0.02 & 0.00 & -0.03 & 0.63 \\
\hline-5.80 & -5.10 & 0.07 & -0.81 & 0.17 & 0.05 & -0.05 & 0.15 & 0.22 & -0.05 & -0.05 & -0.02 & -0.02 & 0.38 \\
\hline-5.54 & -1.01 & -2.78 & 0.55 & -0.60 & 0.11 & -0.22 & -0.22 & 0.11 & -0.02 & 0.02 & -0.02 & -0.02 & 0.14 \\
\hline-4.17 & -8.75 & -3.37 & 0.22 & 0.59 & 0.50 & -0.36 & 0.24 & 0.07 & 0.01 & 0.02 & -0.02 & 0.00 & -0.20 \\
\hline-0.38 & -6.83 & 0.43 & 0.42 & -0.25 & -0.30 & -0.44 & 0.05 & -0.04 & 0.02 & -0.06 & 0.01 & 0.00 & 0.02 \\
\hline-0.12 & -1.87 & -1.89 & -0.50 & 0.05 & -0.45 & -0.15 & 0.06 & -0.04 & 0.09 & -0.01 & -0.02 & -0.01 & -0.45 \\
\hline 3.60 & -3.42 & 1.40 & 0.95 & 0.01 & -0.64 & -0.04 & 0.03 & 0.08 & 0.08 & 0.01 & 0.03 & 0.01 & -0.82 \\
\hline 9.73 & -2.42 & 2.60 & 1.61 & 0.22 & 0.88 & 0.33 & -0.07 & -0.05 & 0.07 & -0.01 & 0.02 & 0.01 & -0.95 \\
\hline 12.12 & 3.49 & -0.49 & -0.31 & -0.21 & 0.25 & 0.29 & -0.25 & -0.11 & 0.04 & -0.05 & 0.02 & 0.04 & -0.96 \\
\hline 16.91 & -0.13 & 2.58 & -0.09 & -0.22 & 0.09 & 0.13 & -0.22 & -0.09 & 0.05 & 0.06 & 0.03 & 0.05 & -1.11 \\
\hline 17.47 & 8.74 & -2.75 & -1.14 & 0.30 & 0.03 & 0.49 & -0.21 & -0.07 & 0.16 & 0.01 & 0.05 & 0.06 & -1.19 \\
\hline
\end{tabular}

TABLE 7: Model summary.

\begin{tabular}{lcccc}
\hline Model & $R$ & $R^{2}$ & $\begin{array}{c}\text { Adjusted } \\
R^{2}\end{array}$ & $\begin{array}{c}\text { Std. error of } \\
\text { the estimate }\end{array}$ \\
\hline 1 & $0.902^{\mathrm{a}}$ & 0.814 & 0.698 & 0.549 \\
\hline
\end{tabular}

${ }^{a}$ First industrial output, FAC_1, FAC_2, FAC_3, FAC_4.

(1) We improve the agricultural irrigation water use efficiency index system. Delphi method could reasonably determine the order of all the indicators, so we used it to get the effective indicators. This method is feasible because we need to know the order of indicators rather than their weighting values for simplifying index system. After the applying of Delphi method, the useful indicators were obtained and then we tried our best to collect the indicators and their data. Members of the investigation team collected the indicators and data sharing out the work and cooperating with one another. Through a variety of channels, means, and mathematical prediction models, each indicator has its own data source for construction of 
TABLE 8: Coefficients.

\begin{tabular}{lcccr}
\hline \multirow{2}{*}{ Model } & \multicolumn{2}{c}{ Unstandardized coefficients } & Standardized coefficients & \multirow{2}{*}{ Sig. } \\
& $\beta$ & Std. error & $\beta$ & -0.020 \\
\hline Constant) & -0.003 & 0.147 & 3.016 & 0.985 \\
FAC_1 & 0.287 & 0.079 & -0.816 & 3.628 \\
FAC_2 & -0.144 & 0.049 & -1.033 & -2.927 \\
FAC_3 & -0.432 & 0.097 & 3.773 & -4.464 \\
FIO & 3.774 & 0.882 & 0.007 \\
FAC_4 & 0.509 & 0.165 & 0.019 \\
\hline
\end{tabular}

TABle 9: Data transformation.

\begin{tabular}{lccccc}
\hline & FAC_1 & FAC_2 & FAC_3 & FAC_4 & Regression \\
& 0.287 & -0.144 & -0.432 & 0.509 & coefficients \\
\hline AP & -0.111 & 0.705 & -0.676 & 0.099 & 0.209 \\
AT & 0.106 & 0.073 & 0.185 & 0.969 & 0.433 \\
RF & 0.012 & -0.854 & 0.328 & 0.092 & 0.032 \\
DI & 0.196 & -0.912 & 0.253 & 0.001 & 0.079 \\
PR & -0.965 & -0.180 & -0.074 & -0.049 & -0.244 \\
AA & 0.680 & -0.480 & -0.233 & -0.097 & 0.316 \\
PA & -0.981 & -0.068 & 0.015 & -0.063 & -0.310 \\
LW & -0.368 & 0.762 & -0.483 & 0.022 & 0.005 \\
PW & -0.557 & 0.715 & -0.373 & 0.015 & -0.094 \\
PWC & 0.338 & 0.581 & 0.650 & -0.205 & -0.372 \\
PIF & 0.973 & 0.205 & -0.032 & -0.031 & 0.248 \\
PGDP & 0.981 & 0.168 & -0.035 & -0.015 & 0.265 \\
RPA & -0.444 & 0.643 & 0.595 & -0.077 & -0.516 \\
GCA & -0.425 & 0.707 & 0.530 & 0.024 & -0.441 \\
CP & 0.573 & 0.735 & 0.283 & 0.073 & -0.026 \\
SST & 0.707 & 0.389 & 0.258 & -0.017 & 0.027 \\
WSIA & 0.986 & -0.024 & -0.114 & 0.042 & 0.357 \\
HWSIA & 0.982 & 0.079 & -0.109 & -0.019 & 0.308 \\
EIA & 0.976 & 0.098 & -0.141 & -0.067 & 0.293 \\
SA & 0.817 & 0.436 & 0.101 & -0.053 & 0.101 \\
WP & 0.928 & -0.164 & -0.180 & 0.027 & 0.381 \\
\hline & & & & &
\end{tabular}

TABLE 10: Five major driven factors.

\begin{tabular}{|c|c|c|}
\hline Indicators & $\begin{array}{l}\text { Regression } \\
\text { coefficients }\end{array}$ & $\begin{array}{c}\text { Driven factor } \\
\text { level }\end{array}$ \\
\hline First industrial output (FIO) & 3.774 & $\begin{array}{c}\text { Very } \\
\text { important }\end{array}$ \\
\hline Rice planting area proportion (RPA) & -0.516 & Important \\
\hline Grain crop area proportion (GCA) & -0.441 & Normal \\
\hline Average temperature per year (AT) & 0.433 & Normal \\
\hline Water price $(\mathrm{WP})$ & 0.381 & Normal \\
\hline
\end{tabular}

agricultural irrigation water use efficiency control system.

(2) Quantitative analysis is in a strong basis of mathematical theory for scientific research. We used the method of correlation coefficient and modified PCA method to analyze the indicators. For eliminating the limitations of PCA, we introduced the MSR to reduce the invalid results, and we abstracted all the principal components to retain the original data. We combine the multiple linear regression with principal components analysis to eliminate the multicollinearity within indicators. The indicators without multicollinearity have been found out by the stepwise regression; then the principal components analysis has been conducted to figure out the principal components of the factors with multicollinearity on the basis of national data in China. As such, the regression equation of irrigation water use efficiency has been constructed. And the major driven factors have been found out because the principal components preserved the original data information.

(3) In this paper, up to different districts and datum years, the authors gave their objective assessment scientifically about the national irrigation development model, saving irrigation style, and saving input and output. Meanwhile, this paper made a conclusion of the processing of irrigation water use efficiency development. Then, the "principal component analysis" (PCA) was applied to eliminate the interfering factors of irrigation water use efficiency; the information included 31 provinces, crossing the period of 1997 to 2010. The study provided the zoning of national irrigation water use efficiency with reference, eliminating the linear interference between indicators and summing up five principal factors.

(4) Outlook about the proposed approach's use in similar problems and its improvement was as follows. The utilization efficiency of irrigation water is in the process of continuous dynamic change, limited or influenced by the national policies and resource endowment. So it is very hard to collect the data of indicators, which causes the subjective index selection inevitably. The proposed approach in this paper will solve this issue effectively and it can be reused in similar problems because of the combination of subjective and objective weighting methods. For example, the ecological problems draw the public attention increasingly nowadays, so it is inevitable to introduce ecological indicators in the assessment of irrigation water use 
efficiency, such as groundwater depth and fertilization frequency in irrigation district. However the popular study methods of ecological indicators are limited to qualitative methods, if this proposed approach in this paper can be adopted, the research results of ecological indicators of irrigation water use will be more convincing.

(5) The improvement of the proposed approach in the future is as follows. Path analysis, a statistical method of testing cause/effect relationships, can effectively explain the impact path of independent variable parameters on the variable factors. Through the analysis of the relationship between the direct and indirect effects on the study, the impact mode of factors can be figured out. As such, we can apply the path analysis to study the mechanism of the effect of driven factors on irrigation water use efficiency. Then the development of irrigation water use efficiency control system is our ultimate goal. Combined with software development technology, we can further research and develop the irrigation water use efficiency control system; the research results of the computation information system also can be applied in the agricultural watersaving management. Through the computer network, the agricultural water-saving information collection, storage, and calculation can be conducted. The agricultural water use monitoring and scheduling also can constantly improve our agricultural water-saving management level; the modern agricultural watersaving management will come true finally.

\section{Additional Points}

(i) Analysis of driven factors affecting irrigation water use efficiency in China.

(ii) Presentation of the process of driven factors screening.

(iii) PCA employed to eliminate the multicollinearity in the modeling.

(iv) Presentation of an integrated approach combining MSR and PCA.

(v) Major driven factors found out using MSR and PCA.

\section{Competing Interests}

The authors declare that they have no competing interests.

\section{Acknowledgments}

This paper was sponsored by the Ministry of Water Resources Special Fund for Scientific Research in the Public Interest (no. 201001020), Ministry of Water Resources Special Fund for Scientific Research in the Public Interest (no. 201201020), and Key laboratory of Water Science and Engineering of Ministry of Water Resources Open Fund for Scientific Research (no. YK914012). The efforts from the reviewers into making positive suggestions and helpful comments to improve the paper are greatly appreciated. Its contents are solely the responsibility of the authors and do not necessarily represent the official views of the Zhejiang University.

\section{References}

[1] J. B. Braden and J. S. Shortle, "Agricultural sources of water pollution," in Encyclopedia of Energy, Natural Resource, and Environmental Economics, vol. 3, pp. 81-85, Elsevier, 2013.

[2] X.-J. Hu, Y.-C. Xiong, Y.-J. Li et al., "Integrated water resources management and water users' associations in the arid region of northwest China: a case study of farmers' perceptions," Journal of Environmental Management, vol. 145, pp. 162-169, 2014.

[3] G. F. Wang, J. C. Chen, F. Wu, and Z. H. Li, "An integrated analysis of agricultural water-use efficiency: a case study in the Heihe River Basin in Northwest China," Physics and Chemistry of the Earth Parts $A / B / C$, vol. 89-90, pp. 3-9, 2015.

[4] J. S. Wallace, "Increasing agricultural water use efficiency to meet future food production," Agriculture, Ecosystems and Environment, vol. 82, no. 1-3, pp. 105-119, 2000.

[5] B. Nunes, D. Bennett, and S. Marques Jr., "Sustainable agricultural production: an investigation in Brazilian semi-arid livestock farms," Journal of Cleaner Production, vol. 64, pp. 414-425, 2014.

[6] C. J. C. Blanco, Y. Secretan, and A. L. A. Mesquita, "Decision support system for micro-hydro power plants in the Amazon region under a sustainable development perspective," Energy for Sustainable Development, vol. 12, no. 3, pp. 25-33, 2008.

[7] S. J. Sun, C. Q. Chen, and Z. C. Qiu, "Current situation of agricultural water use in China and the way of water saving," Liaoning Agricultural Sciences, vol. 1, pp. 35-37, 1999 (Chinese).

[8] National Bureau of Statistics of China, China Statistical Yearbook 2011, Statistics Press, Beijing, China, 2011 (Chinese).

[9] National Bureau of Statistics of China, China Statistical Yearbook 2012, Statistics Press, Beijing, China, 2012 (Chinese).

[10] National Bureau of Statistics of China, China Statistical Yearbook 2013, Statistics Press, Beijing, China, 2013 (Chinese).

[11] X. Y. Wang and L. G. Zhao, "Agricultural water efficiency and the causal factors," Issues in Agricultural Economy, vol. 3, pp. 10-17, 2008 (Chinese).

[12] H. Omrani, R. Gharizadeh Beiragh, and S. Shafiei Kaleibari, "Performance assessment of Iranian electricity distribution companies by an integrated cooperative game data envelopment analysis principal component analysis approach," International Journal of Electrical Power \& Energy Systems, vol. 64, pp. 617625, 2015.

[13] L. L. Fan, Structural Health Monitoring Base on Principal Components Analysis Implemented on a Distributed and Open System, Department of Building \& Construction, City University of Hong Kong, Hong Kong, 2006.

[14] W.-J. Wang, S.-H. Yu, S.-X. Wang, J. Chen, and L. Deng, "Multilevel comprehensive evaluation and decision making of ergonomics," Discrete Dynamics in Nature and Society, vol. 2015, Article ID 689203, 9 pages, 2015.

[15] J. Liu, L. Yan, and C. Ma, "Valuing convertible bonds based on LSRQM method," Discrete Dynamics in Nature and Society, vol. 2014, Article ID 301282, 9 pages, 2014.

[16] P. Y. Han, A. T. Jin, and L. H. Siong, "Eigenvector weighting function in face recognition," Discrete Dynamics in Nature and Society, vol. 2011, Article ID 521935, 15 pages, 2011. 
[17] Z. Wang, Y. Sun, and P. Li, "Functional principal components analysis of Shanghai stock exchange 50 index," Discrete Dynamics in Nature and Society, vol. 2014, Article ID 365204, 7 pages, 2014.

[18] E. E. Abusham and E. K. Wong, "Locally linear discriminate embedding for face recognition," Discrete Dynamics in Nature and Society, vol. 2009, Article ID 916382, 8 pages, 2009.

[19] K. Pearson, "LIII. On lines and planes of closest fit to systems of points in space," PhilMag, vol. 2, no. 11, pp. 559-572, 1901.

[20] K. C. Lam, T. S. Hu, and S. T. Ng, "Using the principal component analysis method as a tool in contractor pre-qualification," Construction Management and Economics, vol. 23, no. 7, pp. 673-684, 2005.

[21] R. R. Hocking, "The analysis and selection of variables in linear regression," Biometrics, vol. 32, no. 1, pp. 1-49, 1976.

[22] N. Draper and H. Smith, Applied Regression Analysis, John Wiley \& Sons, New York, NY, USA, 2nd edition, 1981.

[23] P. L. Flom and D. L. Cassell, "Stopping stepwise: why stepwise and similar selection methods are bad, and what you should use," in Proceedings of the NorthEast SAS Users Group Inc 20th Annual Conference (NESUG '07), Baltimore, Md, USA, November 2007.

[24] F. E. Harrell, Regression Modeling Strategies: With Applications to Linear Models, Logistic Regression, and Survival Analysis, Springer, New York, NY, USA, 2001.

[25] C. Chatfield, "Model uncertainty, data mining and statistical inference," Journal of the Royal Statistical Society Series A: Statistics in Society, vol. 158, no. 3, pp. 419-466, 1995.

[26] B. Efron and R. J. Tibshirani, An Introduction to the Bootstrap, Chapman \& Hall/CRC, 1998.

[27] M. A. Efroymson, "Multiple regression analysis," in Mathematical Methods for Digital Computers, A. Ralston and H. S. Wilf, Eds., Wiley, 1960.

[28] D. P. Foster and E. I. George, "The risk inflation criterion for multiple regression," The Annals of Statistics, vol. 22, no. 4, pp. 1947-1975, 1994.

[29] D. L. Donoho and J. M. Johnstone, "Ideal spatial adaptation by wavelet shrinkage," Biometrika, vol. 81, no. 3, pp. 425-455, 1994.

[30] S.-H. Yoo, J.-Y. Choi, and M.-W. Jang, "Estimation of design water requirement using FAO Penman-Monteith and optimal probability distribution function in South Korea," Agricultural Water Management, vol. 95, no. 7, pp. 845-853, 2008.

[31] J. C. Poussin, A. Imache, R. Beji, P. Le Grusse, and A. Benmihoub, "Exploring regional irrigation water demand using typologies of farms and production units: an example from Tunisia," Agricultural Water Management, vol. 95, no. 8, pp. 973983, 2008.

[32] Y. Ito, K. Momii, and K. Nakagawa, "Modeling the water budget in a deep caldera lake and its hydrologic assessment: Lake Ikeda, Japan," Agricultural Water Management, vol. 96, no. 1, pp. 35-42, 2009.

[33] M. O. Abu-Madi, "Farm-level perspectives regarding irrigation water prices in the Tulkarm district, Palestine," Agricultural Water Management, vol. 96, no. 9, pp. 1344-1350, 2009.

[34] T. R. Green, Q. Yu, L. Ma, and T.-D. Wang, "Crop water use efficiency at multiple scales," Agricultural Water Management, vol. 97, no. 8, pp. 1099-1101, 2010.

[35] M. A. Kahlown, A. Raoof, M. Zubair, and W. D. Kemper, "Water use efficiency and economic feasibility of growing rice and wheat with sprinkler irrigation in the Indus Basin of Pakistan," Agricultural Water Management, vol. 87, no. 3, pp. 292-298, 2007.
[36] I. Hussain, H. Turral, D. Molden, and M.-U. Ahmad, "Measuring and enhancing the value of agricultural water in irrigated river basins," Irrigation Science, vol. 25, no. 3, pp. 263-282, 2007.

[37] A. Z. Salman and E. Al-Karablieh, "Measuring the willingness of farmers to pay for groundwater in the highland areas of Jordan," Agricultural Water Management, vol. 68, no. 1, pp. 61-76, 2004.

[38] M. Huang, T. Dang, J. Gallichand, and M. Goulet, "Effect of increased fertilizer applications to wheat crop on soil-water depletion in the Loess Plateau, China," Agricultural Water Management, vol. 58, no. 3, pp. 267-278, 2003.

[39] F.-M. Li, P. Wang, J. Wang, and J.-Z. Xu, "Effects of irrigation before sowing and plastic film mulching on yield and water uptake of spring wheat in semiarid Loess Plateau of China," Agricultural Water Management, vol. 67, no. 2, pp. 77-88, 2004.

[40] S. Kaneko, K. Tanaka, T. Toyota, and S. Managi, "Water efficiency of agricultural production in China: regional comparison from 1999 to 2002," International Journal of Agricultural Resources, Governance and Ecology, vol. 3, no. 3-4, pp. 231-251, 2004.

[41] H. Jin, W. Qingjie, L. Hongwen, L. Lijin, and G. Huanwen, "Effect of alternative tillage and residue cover on yield and water use efficiency in annual double cropping system in North China Plain," Soil and Tillage Research, vol. 104, no. 1, pp. 198-205, 2009.

[42] R. J. Hutton and B. R. Loveys, "A partial root zone drying irrigation strategy for citrus-effects on water use efficiency and fruit characteristics," Agricultural Water Management, vol. 98, no. 10, pp. 1485-1496, 2011.

[43] A. Wahbi and A. S. A. Shaaban, "Relationship between carbon isotope discrimination $(\Delta)$, yield and water use efficiency of durum wheat in Northern Syria," Agricultural Water Management, vol. 98, no. 12, pp. 1856-1866, 2011.

[44] R. Boelens and J. Vos, “The danger of naturalizing water policy concepts: water productivity and efficiency discourses from field irrigation to virtual water trade," Agricultural Water Management, vol. 108, pp. 16-26, 2012.

[45] B. Bluemling, H. Yang, and C. Pahl-Wostl, "Making water productivity operational-a concept of agricultural water productivity exemplified at a wheat-maize cropping pattern in the North China plain," Agricultural Water Management, vol. 91, no. $1-3$, pp. 11-23, 2007. 


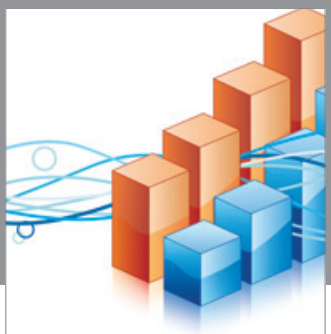

Advances in

Operations Research

vatem alat4

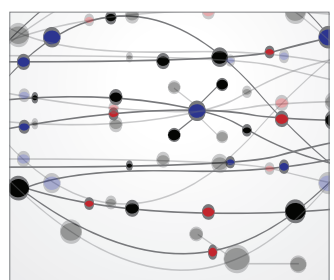

\section{The Scientific} World Journal
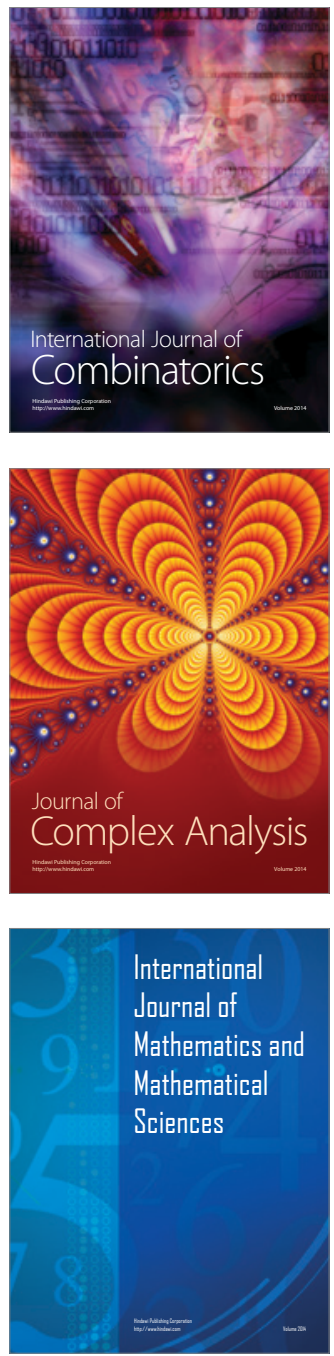
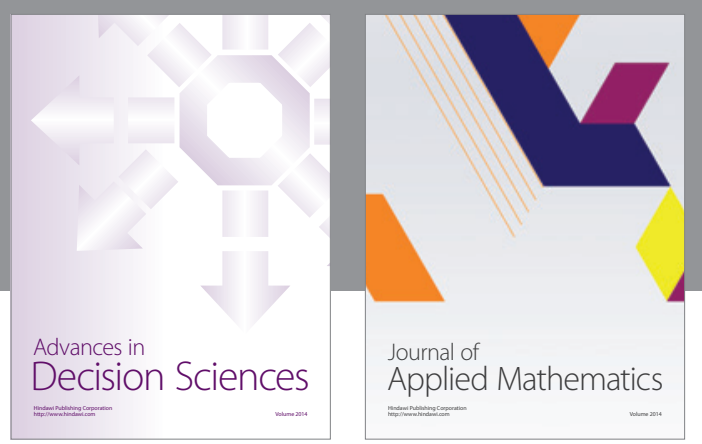

Algebra

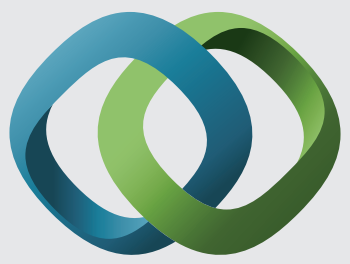

\section{Hindawi}

Submit your manuscripts at

http://www.hindawi.com
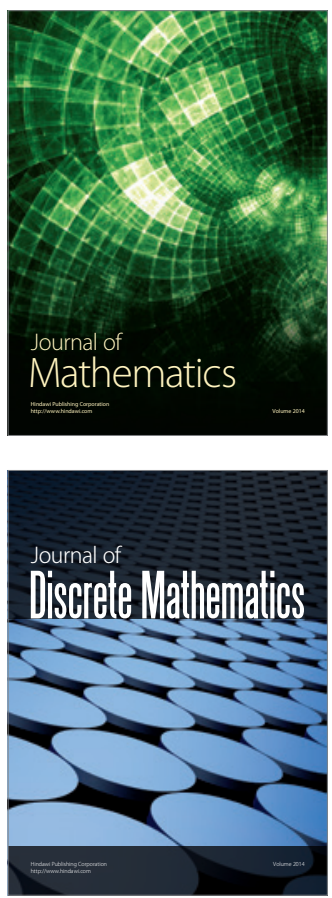

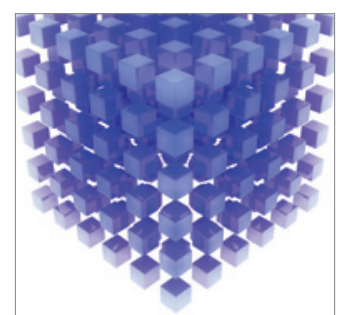

Mathematical Problems in Engineering
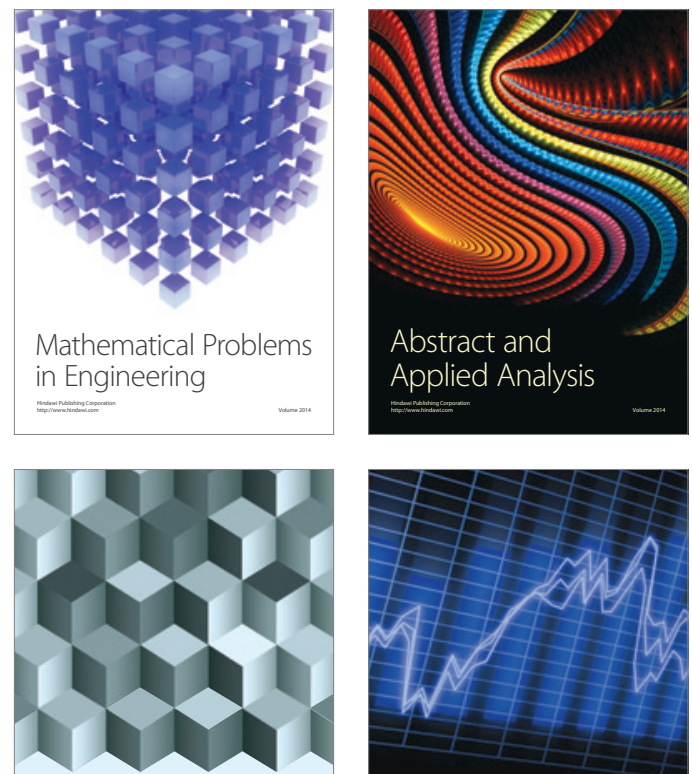

Journal of

Function Spaces

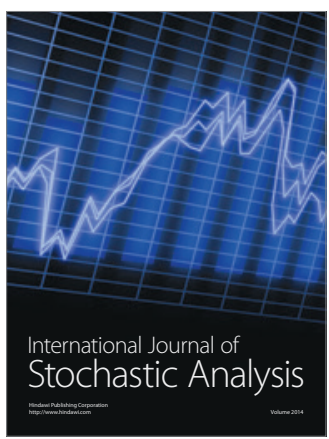

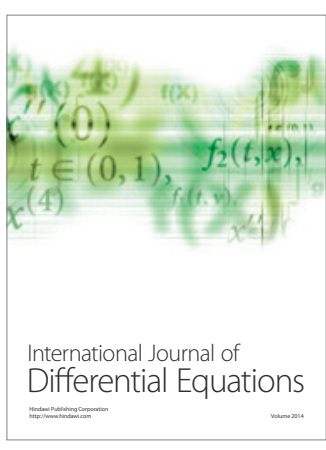
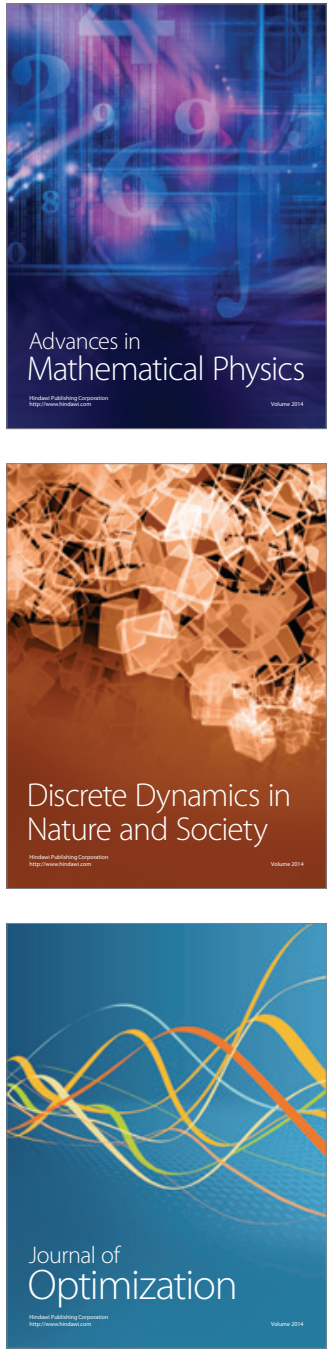